\title{
Development of symmetric and asymmetric straight-through microchannel devices for monodisperse emulsions
}

\author{
Kobayashi, I., Uemura, K., and Nakajima, M.* \\ Food Engineering Division, National Food Research Institute \\ 2-1-12, Kannondai, Tsukuba, Ibaraki 305-8642, Japan,*E-mail: mnaka@affrc.go.jp
}

\begin{abstract}
Microchannel (MC) emulsification is a promising technique for producing monodisperse emulsions with a coefficient of variation of less than $5 \%$ from a microfabricated channel array with a slit-like terrace. We have recently developed an array of deep oblong channels microfabricated vertical to a plate surface as a solution for the low throughput problem of monodisperse emulsion droplets in $\mathrm{MC}$ emulsification. This paper presents novel silicon straight-through MC devices for stable and scaled-up production of monodisperse emulsions. The aspect ratio of symmetric oblong channels with a shorter line of about $10 \mu \mathrm{m}$ and a depth of $200 \mu \mathrm{m}$ affected considerably the droplet generation behavior. The oblong channels exceeding a threshold aspect ratio of approximately 3 were necessary for producing monodisperse soybean oil-in-water $(\mathrm{O} / \mathrm{W})$ emulsions. A large-scale straight-through $\mathrm{MC}$ device including about 211,000 oblong channels was successfully used to produce monodisperse $\mathrm{O} / \mathrm{W}$ emulsions at the maximum droplet productivity of $35 \mathrm{~mL} / \mathrm{h}$. We also present a novel asymmetric straight-through MC where an array of asymmetric channels was microfabricated vertical to the plate surface. This asymmetric straight-through MC enabled stably producing monodisperse emulsions using a to-be-dispersed phase of a very low viscosity (e.g. decane) besides soybean oil, overcoming the major drawback of the symmetric oblong channels. The results obtained in this study concluded that stable and scaled-up production of monodisperse emulsions were achieved by scale-up of a straight-through MC device including appropriate oblong channels and development of an asymmetric straight-through MC.
\end{abstract}

Key words: Straight-through microchannel, Monodisperse emulsion, Symmetric oblong channel, Asymmetric channel, High throughput

\section{Introduction}

An emulsion is a thermodynamically metastable dispersion of two immiscible liquids that is stabilized by surface active components. Emulsion-based products have been utilized in various fields, including foods, pharmaceuticals, and cosmetics. Droplet size and its 
distribution of the emulsions greatly affect many important emulsion properties (Orr, 1983; Mason et al., 1996; McClements, 2004). Monodisperse emulsions with a typical coefficient of variation " $\mathrm{CV}$, (standard deviation/average droplet diameter, $d_{\mathrm{av}}, \times 100$ )" of less than $5 \%$ usually have emulsion stability higher than that of polydisperse emulsions. Monodisperse emulsions also can measure, analyze, and control important emulsion properties more clearly than those of polydisperse emulsions (McClements, 2004). However, conventional emulsification instruments such as dispersing machines, colloid mills, and high-pressure homogenizers usually produce polydisperse emulsions (McClements, 2004).

Mason and Bibette (1997) proposed the production of quasi-monodisperse emulsions by shear-rupturing of polydisperse emulsion droplets in an injection couette mixer. Nakashima et al. (1991) proposed membrane emulsification for producing quasi-monodisperse emulsions with a $\mathrm{CV}$ of approximately $10 \%$. In membrane emulsification, the to-be-dispersed phase is pressed through a microporous membrane to generate size-controlled droplets, while the continuous phase flows across the membrane surface at the low shear stress (Williams et al., 1998; Schröder et al., 1998; Joscelyne and Trägårdh, 1999; Abrahamse et al., 2002). Membrane emulsification using premixed emulsions was effective for the high-throughput production of quasi-monodisperse emulsions (Suzuki et al., 1996; Vladisavljević et al., 2006). Kawakatsu et al. (1997) proposed microchannel (MC) emulsification for procuding monodisperse emulsions from a channel array with a slit-like terrace microfabricated on a silicon plate. The resultant droplet size is primarily controlled by the channel geometry (Kawakatsu et al., 2000; Sugiura et al., 2002). MC emulsification, with a unique droplet generation mechanism driven by interfacial tension, requires no external shear stress to generate droplets (Sugiura et al., 2001). Monodisperse emulsions produced by the preceding techniques have potential food and pharmaceutical applications, including low-calorie fat spread (Katoh et al., 1996), multiple drug emulsions (Higashi, et al., 1995), microcapsules (Muramatsu and Kondo, 1995; Nakagawa et al., 2004), and microparticles (Sugiura et al. 2000; Iwamoto et al., 2002; Wang et al., 2005).

Kobayashi et al. (2002) have proposed a straight-through MC device composed of a channel array vertically microfabricated to the plate surface, which is a solution for the low-throughput problem of monodisperse droplets $(<0.1 \mathrm{~mL} / \mathrm{h})$ in $\mathrm{MC}$ emulsification. A straight-through MC with deep, symmetric oblong channels were capable of producing monodisperse emulsions with $d_{\mathrm{av}}$ of about $30 \mu \mathrm{m}$ at a maximum droplet generation rate of 6.5 $\mathrm{mL} / \mathrm{h}$ (Kobayashi et al., 2002). This straight-through MC device has been applied to the production of monodisperse food-grade emulsions (Kobayashi and Nakajima, 2002; Kobayashi et al., 2005; Saito et al., 2005).

In this paper, we first investigated the effects of the channel aspect ratio and the flow rate of the to-be-dispersed phase on the production characteristics of oil-in-water $(\mathrm{O} / \mathrm{W})$ emulsions using straight-through MCs with symmetric oblong channels. We next developed a large scale straight-through MC plate to improve the throughput capacity of monodisperse emulsions. We 
also propose a novel straight-through MC with asymmetric channels for stable and high-throughput production of monodisperse emulsions, investigating the production characteristics of $\mathrm{O} / \mathrm{W}$ emulsions using the asymmetric straight-through $\mathrm{MC}$.

\section{Materials and methods}

\subsection{Straight-through microchannel plate}

Figure 1(a) schematically depicts the silicon straight-through MC plate of a standard size with about ten thousands of oblong channels within a $10 \times 10 \mathrm{~mm}$ area in the center of the plate. The plate was microfabricated through photolithography, deep-reactive-ion etching, and thermal oxidization processes (Kobayashi et al., 2002). An optical micrograph of the microfabricated oblong channels (Fig. 1(b)) demonstrated that they are of a uniform size. The ratio of the total cross-sectional area of the oblong channels to the total channel area (a 10 -mm square) was $4.4 \%$ in Fig. 1(b).

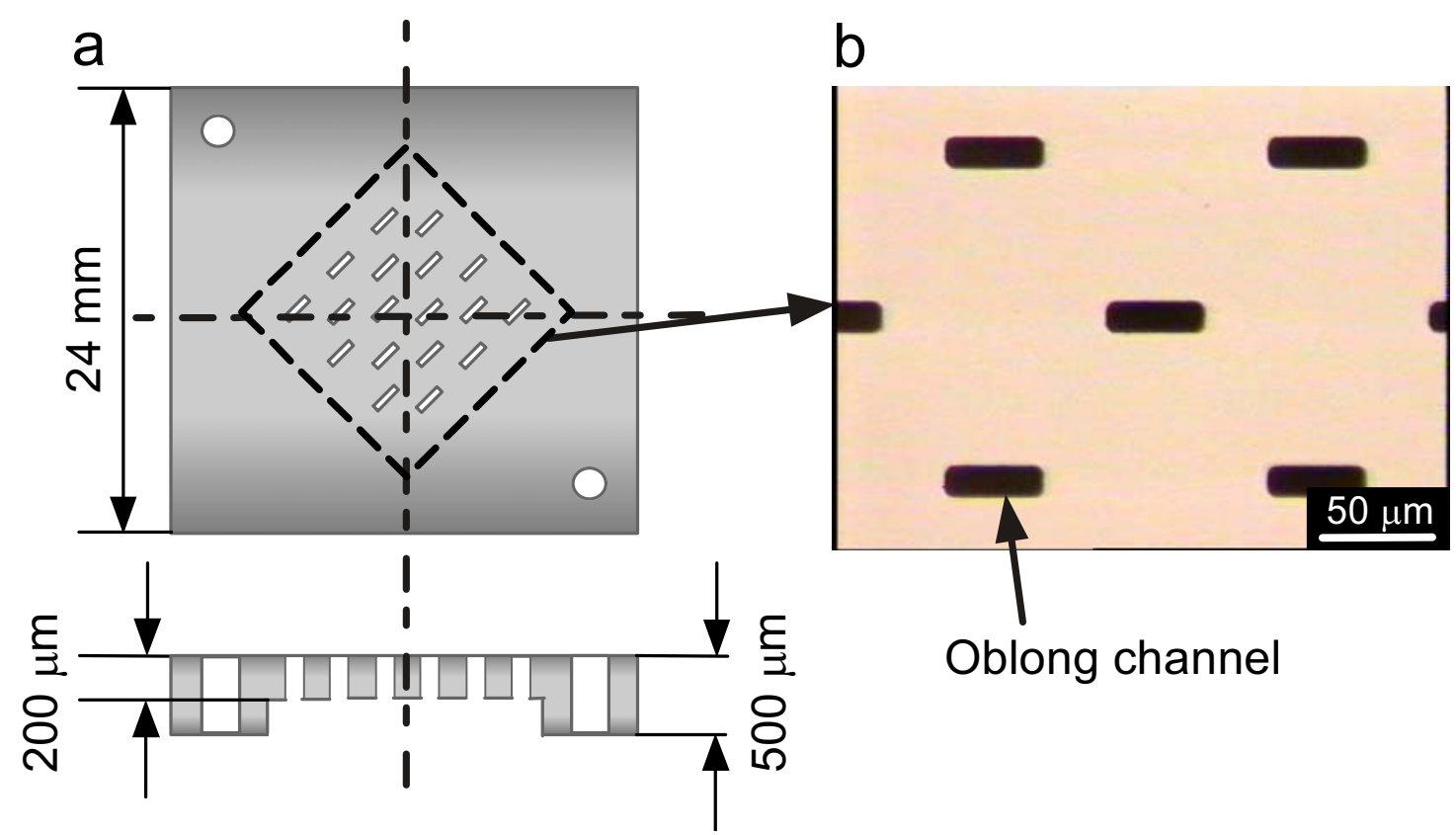

Fig. 1. (a) Schematic of the straight-through MC plate.

(b)Optical micrograph of microfabricated oblong channels.

\subsection{Emulsification procedures and analysis}

We used refined soybean oil or decane (Wako Pure Chemical Ind.) as the to-be-dispersed oil phase and MilliQ water with $1.0 \mathrm{wt} \%$ sodium dodecyl sulfate (SDS, Wako Pure Chemical Ind.) as the continuous water phase. The standard laboratory-scale instrument for straight-through MC emulsification was described previously (Kobayashi et al., 2002). The emulsification module, in which the straight-through MC plate is installed, was initially filled with the continuous phase. The to-be-dispersed phase was supplied into the module by using a 
syringe pump or by lifting a liquid chamber. The to-be-dispersed phase was then pushed out into the gently moving continuous phase via the channels to generate emulsion droplets, as illustrated in Fig. 2. Droplet generation from the channels was microscopically observed during the experiments (Kobayashi et al., 2002). The average droplet diameter $\left(d_{a v}\right)$ and $\mathrm{CV}$ of the formulated emulsions were determined from 200 droplets in the captured images using WinRoof software

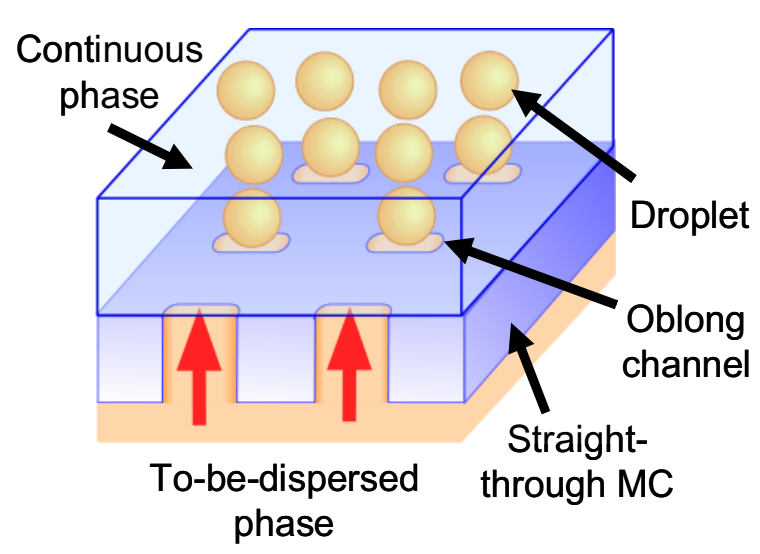

Fig. 2. Schematic of droplet generation from symmetric oblong channels. (Mitani Co. Ltd.).

\section{Results and discussion}

\subsection{Effect of the aspect ratio of symmetric oblong channels}

We used three oblong straight-through MCs with shorter lines of approximately $10 \mu \mathrm{m}$ and channel aspect ratios of 1.9 to 3.8 (Fig. 3). Straight-through MC emulsification experiments using soybean oil as the oil phase were conducted at an average velocity of the continuous phase along the plate surface $\left(V_{\mathrm{c}}\right)$ of $1.2 \mathrm{~mm} / \mathrm{s}$, and a flow rate of the to-be-dispersed phase flux $\left(Q_{\mathrm{d}}\right)$ of $1.0 \mathrm{~mL} / \mathrm{h}$, corresponding to a flux of the to-be-dispersed phase $\left(J_{\mathrm{d}}\right)$ of $10 \mathrm{~L} /\left(\mathrm{m}^{2} \mathrm{~h}\right)$. The oil phase that expanded from the channel exit of TMC-1.9 was transformed into polydisperse large droplets with diameters between 350 and $400 \mu \mathrm{m}$ (Fig. 3(a)). This unstable droplet generation was driven by shear force due to the water-phase flow. The oil phase that expanded from most of active channels in TMC-2.7 was cut off spontaneously into uniformly sized droplets with diameters between 40 and $50 \mu \mathrm{m}$, whereas large droplets with diameters over $350 \mu \mathrm{m}$ were generated from some other active channels (Figs. 3(b) and (d)). As a result, a polydisperse emulsion was obtained using TMC-2.7. When TMC-3.8 was used, all the active channels generated uniformly sized droplets with $d_{\text {av }}$ of 41.9 $\mu \mathrm{m}$ and $\mathrm{CV}$ of $1.9 \%$ (Figs. 3(c) and (e)), demonstrating successful production of a monodisperse emulsion. Our previous paper also reported that the oblong channels with a shorter line of $9.6 \mu \mathrm{m}$ and an aspect ratio of 3.1 were successfully used to produce monodisperse emulsions (Kobayashi et al., 2002). The results reported in this section revealed that there is a threshold channel aspect ratio over which monodisperse emulsions are successfully formulated for the oblong straight- through MCs with shorter lines of about 10 $\mu \mathrm{m}$. 

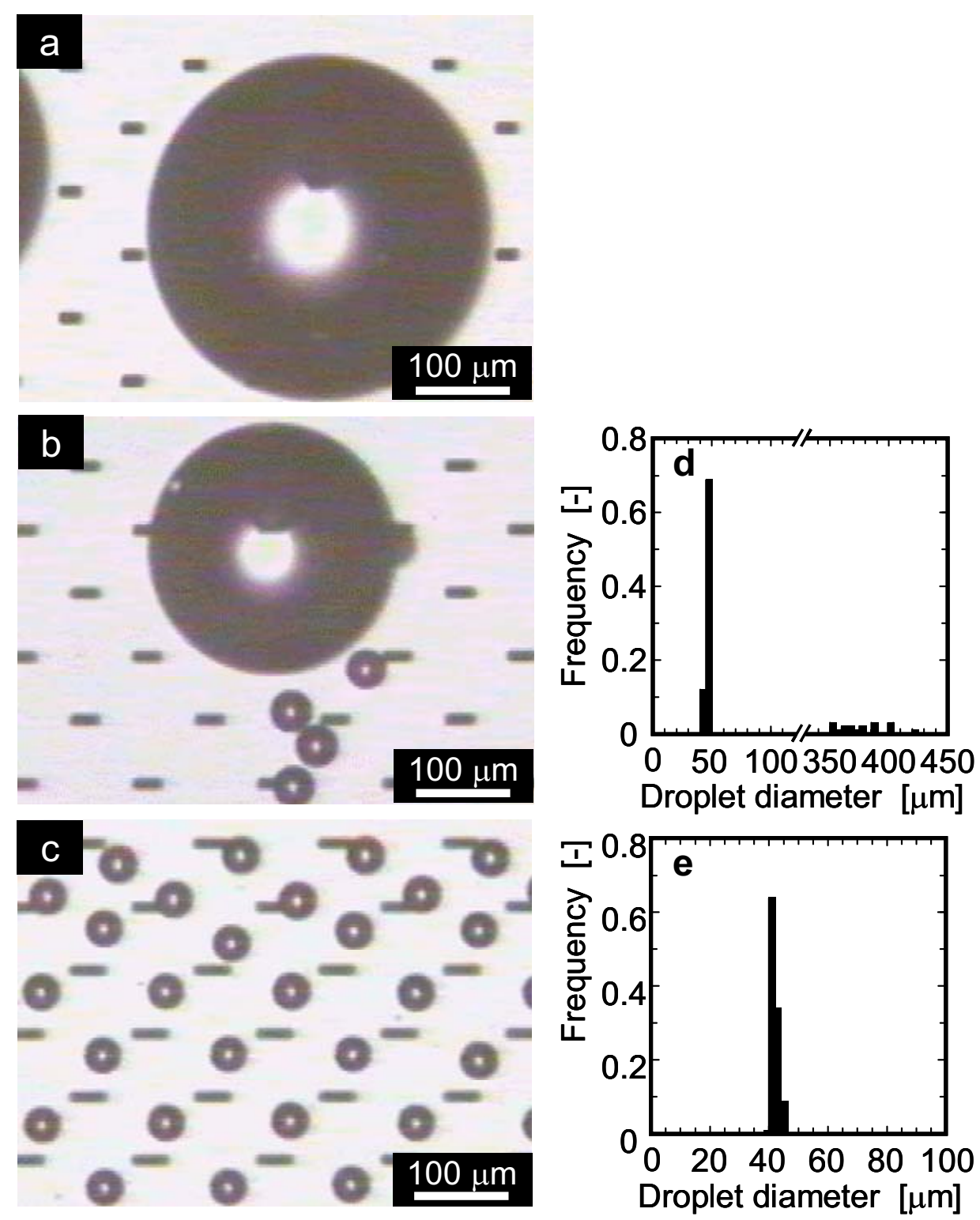

Fig. 3. (a-c) Optical micrographs of droplet generation from symmetric oblong channels. (a) TMC-1.9 with a size of $13.3 \times 25.2 \times 200 \mu \mathrm{m}$ (shorter line $\times$ longer line $\times$ depth), (b) TMC-2.7 with a size of $12.0 \times 32.8 \times 200 \mu \mathrm{m}$, (c) TMC-3.8 with a size of $.10 .8 \times 40.8 \times 200 \mu \mathrm{m}$.

$(\mathrm{d}, \mathrm{e})$ Size distributions of the droplets generated using TMC-2.7 (d) and TMC-3.8 (e).

\subsection{Effect of the flow rate of to-be-dispersed phase}

The oblong straight-through MC (TMC-5.1) used in this section had a channel size of a shorter line of $9.6 \mu \mathrm{m}$, a longer line of $48.7 \mu \mathrm{m}$, and a depth of $200 \mu \mathrm{m}$. We applied $V_{\mathrm{c}}$ of 1.2 $\mathrm{mm} / \mathrm{s}$ and $Q_{\mathrm{d}}$ of 1.0 to $10.0 \mathrm{~mL} / \mathrm{h}$ during the emulsification experiments. Figure 4 shows the effect of $Q_{\mathrm{d}}$ on $d_{\mathrm{av}}$ and $\mathrm{CV}$ of the produced emulsions. Monodisperse soybean oil-in-water emulsions with $d_{\mathrm{av}}$ of about $40 \mu \mathrm{m}$ and $\mathrm{CV}$ of less than $3 \%$ were stably produced using the TMC-5.1 at $Q_{\mathrm{d}}$ of $6.0 \mathrm{~mL} / \mathrm{h}$ or less (Fig. 4(a)). The $d_{\mathrm{av}}$ values were independent of the applied $Q_{\mathrm{d}}$ in this region (. The average droplet generation rate of each active channel in the region (a) increased with increasing $Q_{\mathrm{d}}$ and reached six droplets/s. The $d_{\mathrm{av}}$ and CV values significantly 
increased with increasing $Q_{\mathrm{d}}$ between 7.0 and $9.0 \mathrm{~mL} / \mathrm{h}$ (Fig. 4(b)). Quasi-monodisperse emulsions with $\mathrm{CV}$ of 8 to $15 \%$ were obtained in the region (b) as an optical micrograph in Fig. 4(b) depicts. The oil phase that expanded from the channel exit was spontaneously cut off into droplets in the regions (a) and (b). A drastic increase in the $d_{\mathrm{av}}$ and CV values was observed at $Q_{\mathrm{d}}$ of $10.0 \mathrm{~mL} / \mathrm{h}$ (Fig. 4(c)); a polydisperse emulsion with large droplets was obtained in the region (c). Steric hindrance among the neighboring oil phase droplets restricted their further expansion and forced them to detach from the channel exit. The oil phase that expanded from the channel exit was no longer cut off spontaneously in the region (c). We thus demonstrated the existence of a critical $Q_{\mathrm{d}}$ value over which the droplet generation behavior and droplet size distribution significantly change in straight-through $\mathrm{MC}$ emulsification.

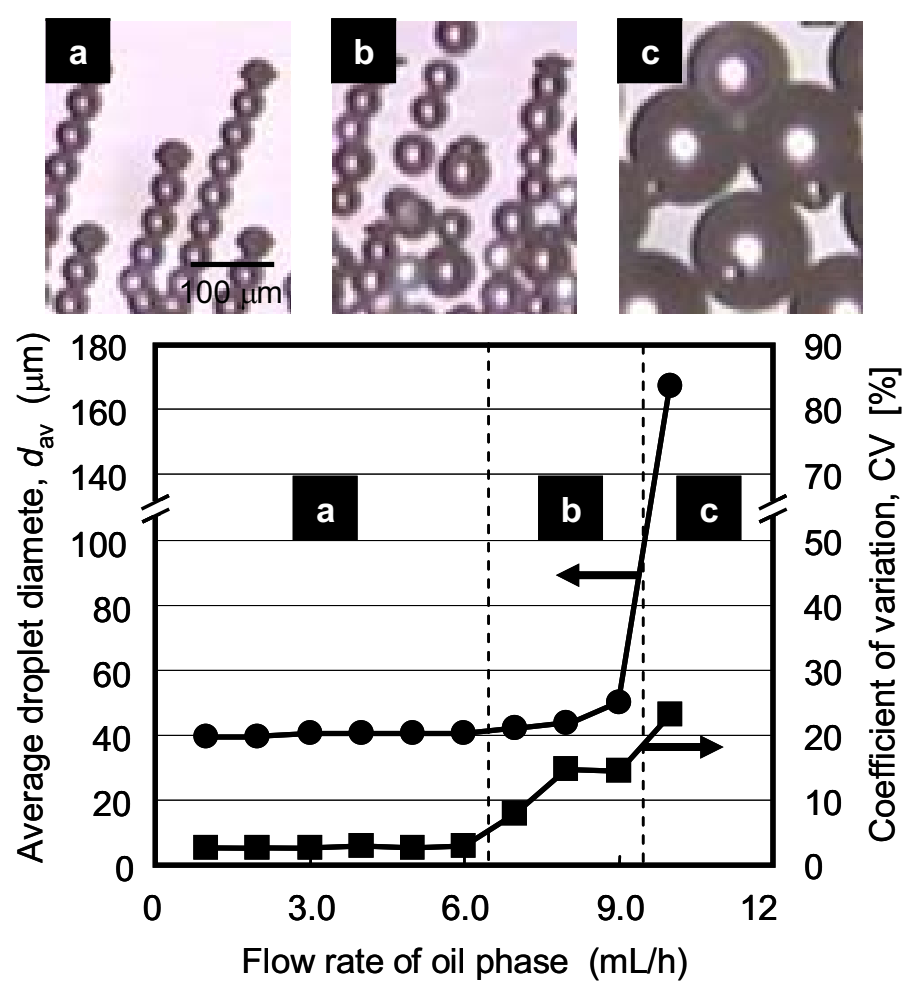

Fig. 4. Effect of $Q_{\mathrm{d}}$ on $d_{\mathrm{av}}$ and $\mathrm{CV}$ of $\mathrm{O} / \mathrm{W}$ emulsions produced using TMC5.1.

\subsection{Scale up of straight-through MC device with symmetric oblong channels}

Figure 5 presents the silicon straight-through MC plate of a large size with about 221,000 oblong channels within four $15 \times 15 \mathrm{~mm}$ areas in the plate. The oblong channels fabricated in the plate had a channel size of a shorter line of $6.6 \mu \mathrm{m}$, a longer line of $26.7 \mu \mathrm{m}$, and a depth of $100 \mu \mathrm{m}$. The effective channels area of this plate exceeded that of the standard straight-through MC plate (Fig. 1(a)) by about ten times. We applied $V_{\mathrm{c}}$ of $2.2 \mathrm{~mm} / \mathrm{s}$ and $Q_{\mathrm{d}}$ of 10.0 to $35.0 \mathrm{~mL} / \mathrm{h}$ during the emulsification experiments. At $Q_{\mathrm{d}}$ of $10.0 \mathrm{~mL} / \mathrm{h}$, a monodisperse soybean oil-in-water emulsion with $d_{\mathrm{av}}$ of $30.1 \mu \mathrm{m}$ and $\mathrm{CV}$ of $3.9 \%$ was stably produced from 
active channels. $Q_{\mathrm{d}}$ was then increased in steps. Maximum $60 \%$ of active channels stably generated monodisperse droplets with $d_{\mathrm{av}}$ of $30.2 \mu \mathrm{m}$ and $\mathrm{CV}$ of $3.3 \%$ at $Q_{\mathrm{d}}$ of $35.0 \mathrm{~L} /\left(\mathrm{m}^{2} \mathrm{~h}\right)$, corresponding to $J_{\mathrm{d}}$ of $38.5 \mathrm{~L} /\left(\mathrm{m}^{2} \mathrm{~h}\right)$. In this case, the droplet generation rate per a single device was about 674,000 droplets/s and each active channel generated five droplets per second in average. The above-mentioned results demonstrated that the throughput capacity of monodisperse droplets in a straight-through $\mathrm{MC}$ emulsification device was scaled up to several tens of $\mathrm{mL} / \mathrm{h}$

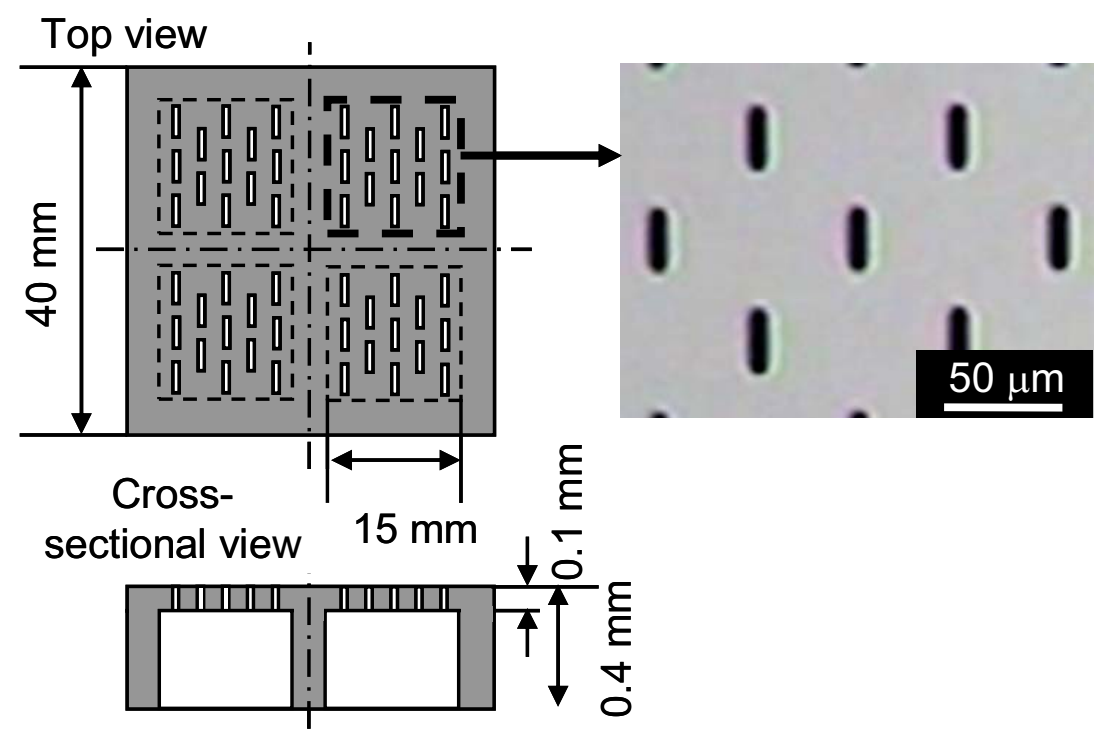

Fig. 5. Schematic of a silicon straight-through MC plate and optical micrograph of symmetric oblong channels.

\subsection{Emulsification using an asymmetric straight-through $M C$}

Figure 6 presents an asymmetric straight-through MC consisted of circular channels $(9.5$ $\mu \mathrm{m}$ in diameter and $5.4 \mu \mathrm{m}$ in depth) and slits $(104 \mu \mathrm{m}$ in longer line, $11 \mu \mathrm{m}$ in shorter line, and $21 \mu \mathrm{m}$ in depth). The SEM micrographs in Figs. 6(b) and (c) confirmed that the slits and channels had highly narrow size distributions.

We examined emulsion droplet generation using the asymmetric straight-through MC. The pressure applied to the oil phase $\left(P_{\mathrm{d}}\right)$ was gradually increased during the emulsification experiments. Figures 7(a) and (b) depict examples of droplet generation using the asymmetric straight-through MC. The oil phase that passed through the asymmetric channels expanded into the water phase domain over the plate surface and was spontaneously cut into uniformly sized droplets both for the decane- and soybean oil-containing systems. This result demonstrated that the asymmetric channels overcome the major drawbacks of the symmetric oblong channels: unstable generation of polydisperse large droplets for low viscosity oil-containing systems. The emulsions produced using the asymmetric straight-through MC had $d_{\mathrm{av}}$ and $\mathrm{CV}$ of $40.9 \mu \mathrm{m}$ and $1.3 \%$ for decane and of $34.9 \mu \mathrm{m}$ and $1.9 \%$ for soybean oil (Figs. 7(c) and (d)); they are of monodisperse. The ratio of the $d_{\mathrm{av}}$ value to the shorter line of 
the slit ranged from 3.2 to 3.7, analogous to those in membrane emulsification (Nakashima et al., 1991) and MC emulsification (Kawakatsu et al., 1997). The average droplet generation rate from each active channel reached maximum values of 50 droplet/s for decane and 10 droplets/s for soybean oil. We can explain the advantages of the asymmetric straight-through $\mathrm{MC}$ as follows. The circular channel with a minimum cross-sectional area more effectively controls the oil-phase flow in the channel than in the oblong channel because of the greater pressure drop in the circular channel. Moreover, the oil phase that expands in the slit with a distorted, disklike shape can work as a condenser to prevent continuous outflow of the oil phase. We therefore consider that both the slit and circular channel contribute to the stable generation of monodisperse droplets, even using a low viscosity to-be-dispersed phase.
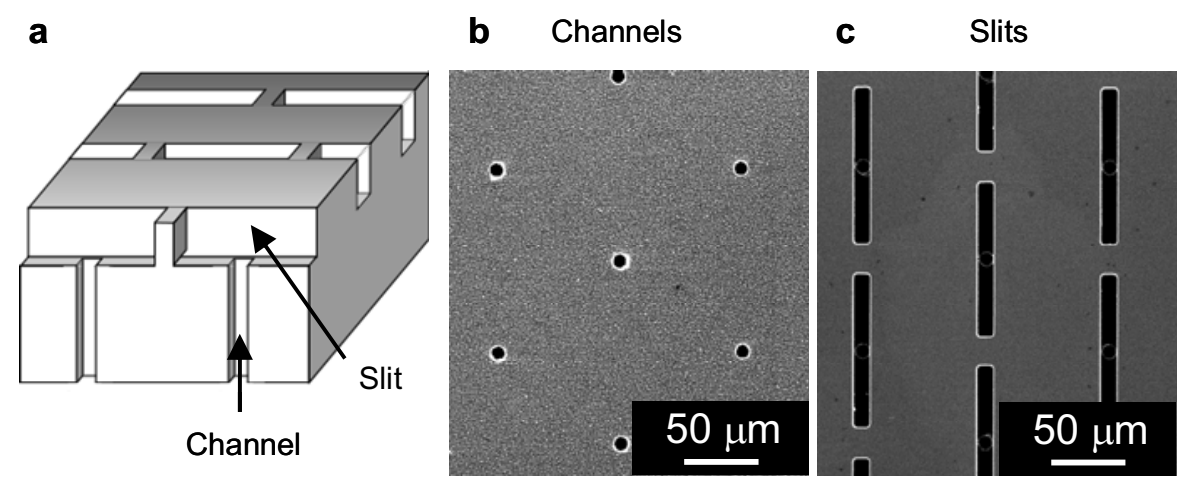

Fig. 6. (a) Schematic of an asymmetric straight-through MC. $(b, c)$ SEM micrographs of channels and slits.
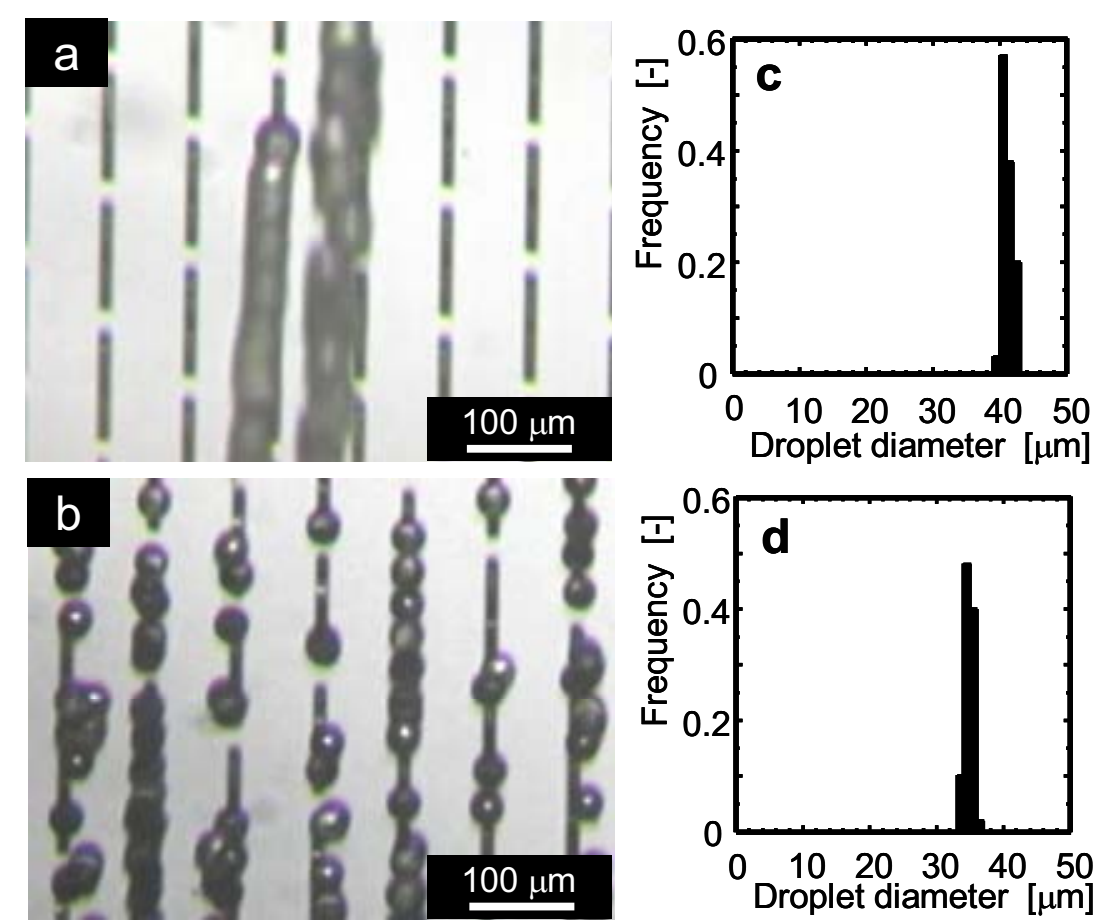

Fig. 7. (a,b) Optical micrographs of generation of $\mathrm{O} / \mathrm{W}$ emulsion droplets using the asymmetric straight-through MC. (a) Decane, $P_{\mathrm{d}}: 2.65 \mathrm{kPa}$, (b) Soybean oil, $P_{\mathrm{d}}: 3.60 \mathrm{kPa}$.

$(\mathrm{c}, \mathrm{d})$ Size distributions of the resultant decane droplets (c) and soybean oil droplets (d). 


\section{Conclusions}

This paper clarified the $\mathrm{MC}$ and device structure appropriate for stable production of monodisperse emulsions at high droplet generation rates. Symmetric oblong channels with aspect ratios exceeding the threshold value of about 3 were required for producing monodisperse emulsions. Below the critical $Q_{\mathrm{d}}$, monodisperse emulsions were successfully produced and their $d_{\mathrm{av}}$ and $\mathrm{CV}$ values were independent of the $Q_{\mathrm{d}}$ value. Above the critical $Q_{\mathrm{d}}$, we observed generation of quasi-monodisperse droplets and of polydisperse large droplets. The throughput capacity of monodisperse droplets in straight-through MC emulsification was scaled up to several tens of $\mathrm{mL} / \mathrm{h}$ using the large scale straight-through $\mathrm{MC}$ plate. The novel asymmetric straight-through MC consisted of slits and circular channels enabled producing monodisperse emulsions, even using a to-be-dispersed phase with a very low viscosity of smaller than $1 \mathrm{mPa}$.

\section{Acknowledgement}

This study was supported by the Nanotechnology Project of Ministry of Agriculture, Forestry and Fishery of Japan.

\section{Literatures cited}

Abrahamse, A. J., van Lierop, R., van der Sman, R. G. M., van der Padt, A, and Boom, R. M., (2001). Journal of Membrane Science, 204, 127.

Higashi, S., Tabata, N., Nakashima, T., Iwata, K., Uchiyama, F., Tamura, S., and Setoguti, T. (1995). Cancer, 75, 1245.

Iwamoto, S., Nakagawa, K., Sugiura, S., and Nakajima, M., (2002). AAPS PharmSciTech, 3(3), article 25.

Joscelyne, S.M. and Trägårdh, G., J., (1999). Journal of Food Engineering, 39, 59.

Katoh, R., Asano, Y., Fujita, A., Sotoyama, K., and Tomita, M. (1996). Journal of Membrane Science, 113, 131.

Kawakatsu, T., Kikuchi, Y., and Nakajima, M., (1997). Journal of American Oil Chemists' Society, 74, 317.

Kawakatsu, T., Trägårdh, G., Kikuchi, Y., Nakajima, M., Komori, H., and Yonemoto, T. (2000). Journal of Surfactants and Detergents, 3, 295.

Kobayashi, I., Nakajima, M., Chun, K., Kikuchi, Y., and Fujita, H., (2002). AIChE Journal, $48,1639$.

Kobayashi, I. and Nakajima, M., (2002). European Journal of Lipid Science and Technology, 104, $720-727$.

Kobayashi, I., Mukataka, S., and Nakajima, M., (2005). Journal of American Oil Chemists' Society, 82, 65.

Mason, T. G., Krall, A. H., Gang, H., Bibette, J., and Weitz, D. A. (1996). Monodisperse 
emulsions: Properties and used. In: In P. Becher (Ed.), Encyclopedia of emulsion technology, (vol. 4, pp. 299-335). Marcel Dekker, New York, U.S.A.

Mason, T. G. and Bibette, J. (1997). Langmuir, 13, 4600.

McClements, D. J. (2004). Food emulsions: Principles, practice and techniques, 2nd ed, (pp. 1-24). CRC Press, Boca Raton, U.S.A.

Muramatsu, N. and Kondo, T. (1995). Journal of Microencapsulation, 12, 129.

Nakagawa, K., Iwamoto, S., Nakajima, M., Shono, A., and Satoh, K. (2004). Journal of Colloid and Interface Science, 278, 198.

Nakashima, T., Shimizu, M., \& Kukizaki, M. (1991). Key Engineering Materials, 61/62, 513.

Orr, C. (1983). Emulsion droplet size data. In P. Becher (Ed.), Encyclopedia of emulsion technology, (vol. 1, pp. 269-403). Marcel Dekker, New York, U.S.A.

Williams, R. A., Peng, S. J., Wheeler, D. A., Morley, N. C., Taylor, D., Whalley, M., Houldworth, D. W., (1998). Chemical Engineering Research Destination A, 76, 902.

Saito, M., Yin., L.-J., Kobayashi, I., and Nakajima, M., (2005). Food Hydrocolloids, 19, 745.

Schröder, V., Behrend, O., and Schubert, H., (1998). Journal of Colloid and Interface Science, $202,334$.

Sugiura, S., Nakajima, M., Tong, J., Nabetani, H., and Seki, M., (2000). Journal of Colloid and Interface Science, 227, 95.

Sugiura, S., Nakajima, M., Iwamoto, S., and Seki, M., (2001). Langmuir, 17, 5562.

Sugiura, S., Nakajima, M., Kumazawa, N., Iwamoto, S., and Seki, M., (2002). Journal of Physical Chemistry B, 106, 9405.

Suzuki, K., Shuto, I., and Hagura, Y., (1996). Food Science and Technology International Tokyo, 2, 43.

Vladisavljević, G. T., Surh, J., and McClements, J. D., (2006). Langmuir, 22, 4526.

Wang, L.-Y., Ma, G.-H., and Su, A.-G., (2005). Journal of Controlled Release, 106, 62. 